\title{
SGLT2-Inhibitor-Induced Euglycemic Diabetic Ketoacidosis in a Newly Diagnosed Type 1 Diabetes Patient
}

\author{
Mohammad Aljumah ${ }^{1}$, Mohammad Najeeb ${ }^{1}$ and Dina Omar ${ }^{2 *}$ \\ ${ }^{1}$ Mubarak Al-kabeer Hospital, Kuwait \\ ${ }^{2}$ Dasman Diabetes Institute, Kuwait \\ Submission: November 19, 2018; Published: December 05, 2018 \\ *Corresponding author: Dina Omar, Dasman Diabetes Institute, Jasim Mohamad Al Bahar St, Al Kuwayt, Kuwait
}

Abstract

Euglycemic Diabetic Ketoacidosis (DKA) is a medical emergency wherein the patient presents with DKA and a normal blood glucose. This can make diagnosis difficult. We report a patient with type 1 diabetes (T1D) who was prescribed the relatively new Sodium-glucose cotransporter 2 (SGLT2) inhibitor and consequently presented with euglycemic DKA.

Keywords: Euglycemic Diabetic Ketoacidosis (DKA); Sodium-Glucose Cotransporter 2 (SGLT2) Inhibitor, Type 1 Diabetes

\section{Introduction}

SGLT2 inhibitors are a relatively new class of oral hypoglycemic agents indicated for type 2 diabetes (T2D). They inhibit glucose reabsorption from urine at the proximal renal tubules by targeting SGLT2. The drugs are reported to have a relatively pronounced glucose-lowering effect with a low risk of hypoglycemia when administered as monotherapy [1]. However, when prescribed for patients with T1D, they can cause euglycemic DKA, which is DKA characterized by a normal blood glucose level at presentation.

\section{Case Report}

A 28 years old Iraqi female, known to have T2D on therapy, presented with features of DKA but with normal blood glucose $(7.5 \mathrm{mmol} / \mathrm{L})$. She was diagnosed with T2D about a month before her admission to our hospital. On presentation, her Body Mass Index was $20.5 \mathrm{~kg} / \mathrm{cm} 2$ (Height $156 \mathrm{~cm}$, body weight $50 \mathrm{~kg}$ ). Family history was positive for hypothyroidism in mother, but not for diabetes in her family. She gave no history of DKA prior to this admission. At the time of diagnosis one month earlier, she had presented with a 3-week history of hyperosmolar symptoms typical of diabetes mellitus and weight loss of $7 \mathrm{~kg}$. Then she had presented with a random blood glucose of $22 \mathrm{mmol} / \mathrm{L}$. Her HbA1c was $9.5 \%$. Her physician had started her on Metformin $500 \mathrm{mg}$ thrice daily. After about 2 weeks, she complained of poor glycemic control despite compliance to diet and Metformin. Glipalamide $5 \mathrm{mg} /$ day and dapagliflozin $(10 \mathrm{mg} /$ day $)$ were added after the patient refused to take insulin as recommended. Within 2 weeks of this therapy, she complained of epigastric pain for two days associated with nausea and vomiting and decreased appetite. She also complained of vaginal itching/irritation. There were no infectious diseases evidenced by chest X-ray, electrocardiogram, and urinary sediments and blood culture. Table 1 shows her laboratory findings on admission and follow up. Other investigations on follow up are presented in Table 2. Unfortunately, her initial laboratory finding at the diagnosis of T2D was not available.

Table 1: Laboratory data at admission and follow up of case. ALT: Alanine Transferase; AST: Aspartate Aminotransferase; BUN: Blood Urea Nitrogen; Cr: Creatinine; Na: Sodium; K: Potassium; CO2: bicarbonate

\begin{tabular}{|c|c|c|c|}
\hline & At Admission & Day $\mathbf{1}$ & Day $\mathbf{2}$ \\
\hline FBS $(\mathrm{mmol} / \mathrm{L})$ & 7.5 & 4.3 & 4.8 \\
\hline Na $(\mathrm{mmol} / \mathrm{L})$ & 133 & 137 & 137 \\
\hline K $(\mathrm{mmol} / \mathrm{L})$ & 4.63 & 3.74 & 3.57 \\
\hline AST $(\mathrm{IU} / \mathrm{L})$ & 42 & & \\
\hline ALT (IU/L) & 46 & & \\
\hline Amylase (IU/L) & 32 & 0.8 & 0.4 \\
\hline BUN (mmol/L) & 2.6 & & \\
\hline
\end{tabular}




\section{Journal of Endocrinology and Thyroid Research}

\begin{tabular}{|c|c|c|c|}
\hline $\mathbf{C r}(\mathrm{umol} / \mathrm{L})$ & 59 & 33 & 31 \\
\hline $\mathbf{C O 2}(\mathrm{mmol} / \mathrm{L})$ & 8 & 15 & 19 \\
\hline Anion gap $(\mathrm{mmol} / \mathrm{L})$ & 24.6 & 11.7 & 10.6 \\
\hline Lactate $(\mathrm{mmol} / \mathrm{L})$ & 1.11 & & NA \\
\hline TSH $(\mathrm{ulu} / \mathrm{ml})$ & & & 0.69 \\
\hline Free T4 $(\mathrm{pmol} / \mathrm{L})$ & & & 12.1 \\
\hline Protein/creatinine ratio $(\mathrm{gm} / \mathrm{gm})$ & & & 1.392 \\
\hline Urine creatinine (mmol/L) & & & 1.20 \\
\hline Urine protein $(\mathrm{mg} / \mathrm{L})$ & & 189 \\
\hline Blood gas analysis-pH & 7.121 & 7.35 \\
\hline Ketone in urine analysis & +++ & & \\
\hline Glucose in urine analysis & ++ & & \\
\hline
\end{tabular}

Table 2: Follow up characteristics of case. AB: Antibody; GAD: Glutamic Acid Decarboxylase; IA-2: Insulin Autoimmune-2.

\begin{tabular}{|c|c|}
\hline FBS & $8 \mathrm{mmol} / \mathrm{L}$ \\
\hline HbA1c & $9.50 \%$ \\
\hline C-peptide & $69 \mathrm{pmol} / \mathrm{L}$ \\
\hline Anti-GAD Ab & POSITIVE \\
\hline Insulin Ab & POSITIVE \\
\hline
\end{tabular}

\section{Results}

We stopped all her above medications. She was managed for DKA with continuous intravenous (IV) insulin and appropriate IV fluids. The patient had responded well to our management in the hospital. Her condition greatly improved after one day from admission. She was free of ketoacidosis and had resumed oral feeding with multiple daily injections of insulin (MDI). She was discharged on insulin as part 4 units thrice daily (as bolus before each meal) and insulin Glargine 4 units as basal insulin at bed time.

\section{Discussion}

SGLT2 inhibitors are a promising class of antidiabetic agents that have recently become more popular. Their main adverse effects are reported to be genital fungal infections, bacterial urinary tract infections and polyuria. Volume depletion has also been reported particularly in elderly in in patients on concurrent loop diuretics [2]. These oral antidiabetic agents can produce weight loss of about $2-3 \mathrm{~kg}$, secondary to the $280-320 \mathrm{kcal} /$ day loss as $70-80 \mathrm{~g}$ of glucose is excreted in the urine $[3,4]$. Since patients with T2DM are usually more obese than those without diabetes, SGLT2 inhibitors may be the first choice of an oral hypoglycemic agent after metformin. However, weight loss could be a concern for patients with low body weight $[3,4]$. DKA is often associated with T1DM and severe hyperglycemia is a cardinal feature. Recently, there have been case reports of DKA in patients with T1DM and T2DM treated with SGLT2 inhibitors [1]. SGLT-2 inhibitor- associated DKA were also more common in patients with T1DM, rather than those with T2DM. In contrast to traditional DKA, they do not show severe hyperglycemia, and are therefore called euglycemic DKA. The absence of significant hyperglycemia in these patients made their detection and treatment delayed by physicians and patients [1]. SGLT- 2 inhibitors may potentiate the generation of ketoacidosis despite achieving euglycemia through various mechanisms. Increase in glucagon in the background of an insulin deficient state, increased reabsorption of ketone with concomitant delayed clearance of ketone, shift in substrate utilization to fatty acid with concomitant increase in ketone body production, and weight loss with concomitant sarcopenia are mechanisms that could be playing complementary roles in the genesis of ketonemia. Associated dehydration, fluid loss (gastroenteritis) or poor fluid intake (vomiting) and infections, in a poor metabolic milieu, might also trigger the process of this event, making the patient ketosis prone thus precipitating a DKA with normal blood glucose levels [5]. So far, Euglycemic DKA due to SGLT2 inhibitors has been reported in patients with T1DM, and the FDA has contraindicated their routine use in such patients. Our patient also appears to have T1DM. She was later found to have positive anti GAD and anti-insulin antibodies as well as low c-peptide levels. In addition, her acute clinical presentation with DKA within one month of being diagnosed with diabetes, indicates an insulin deficient state. This case is an attestation to the FDA advice that SGLT2 inhibitors must not be routinely prescribed to patients with T1DM.

\section{Conclusion}

SGLT2 inhibitors should not be routinely used in patients with type $1 \mathrm{DM}$ as add on therapy because of the adverse effect of euglycemic DKA. It poses a challenge to physicians as patients present with normal serum glucose levels and ketoacidosis may be overlooked. Despite euglycemia, ketoacidosis remains a medical emergency and must be treated quickly and appropriately [6]. Therefore, SGLT2 inhibitor should be considered as a cause in patients presenting with DKA.

\section{References}

1. Peters AL, Buschur EO, Buse JB, Cohan P, Diner JC, et al. (2015) Euglycemic diabetic ketoacidosis: a potential complication of treatment with sodium-glucose cotransporter 2 inhibition. Diabetes Care 38(9): 1687-1693.

2. Boyle LD, Wilding JP (2014) A safety evaluation of canagliflozin: a firstin-class treatment for type 2 diabetes. Expert Opin Drug Saf 13(11): $1535-1544$ 
3. Monami M, Nardini C, Mannucci E (2014) Efficacy and safety of sodium glucose cotransport- 2 inhibitors in type 2 diabetes: a meta-analysis of randomized clinical trials. Diabetes Obes Metab 16(5): 457-466.

4. Vasilakou D, Karagiannis T, Athanasiadou E, Mainou M, Liakos A, et al. (2013) Sodium-glucose cotransporter 2 inhibitors for type 2 diabetes: a systematic review and meta-analysis. Ann Intern Med 159(4): 262274.

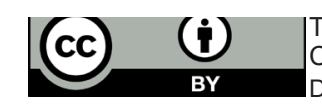

This work is licensed under Creative Commons Attribution 4.0 Licens

DOI: DOI: 10.19080/JETR.2018.04.555627
5. Singh AK (2015) Sodium-glucose co-transporter-2 inhibitors and euglycemic ketoacidosis: Wisdom of hindsight. Indian J Endocrinol Metab 19(6): 722-730.

6. Jenkins D, Close CF, Krentz AJ, Nattrass M, Wright AD (1993) Euglycaemic diabetic ketoacidosis: does it exist? Acta Diabetol 30(4): 251-253.

\section{Your next submission with Juniper Publishers} will reach you the below assets

- Quality Editorial service

- Swift Peer Review

- Reprints availability

- E-prints Service

- Manuscript Podcast for convenient understanding

- Global attainment for your research

- Manuscript accessibility in different formats

( Pdf, E-pub, Full Text, Audio)

- Unceasing customer service

Track the below URL for one-step submission https://juniperpublishers.com/online-submission.php 